\title{
수요자 맞춤형 공학커뮤니케이션 교육프로그램 구성체계 개발
}

김태현 $(\text { 金泰鉉 })^{*}$ 진성희 $(\text { 陳成姬 })^{* \star}$

\section{논문 요약}

과학기술의 세계화와 학문간 융합과 협력이 활발하게 이루어지면서 공학교육분야에서도 개별 공학분야의 전 문성을 강조하던 경향에서 전문적 소양을 증진시키는데 관심을 기울이고 있다. 이러한 사회적 요구에 부응하여 공학도들의 커뮤니케이션 능력을 증진시키고자 하는 목적으로 전국의 공학계열대학에서는 공학커뮤니케이션 교과목을 개설운영하고 있다. 그러나 해당 분야에 대한 전문가의 부족으로 인하여 교과목을 담당하는 교수자의 배경지식에 따라 교수자주도적으로 교육내용을 구성하여 운영해 오고 있는 것이 현실이다. 따라서 이 연구에서 는 수요자의 요구에 부합하는 맞춤형 공학커뮤니케이션 교육프로그램 구성체계를 개발하고자 하였다. 이를 위해 공학커뮤니케이션에 대한 이론적 탐색으로써 국내외 공학커뮤니케이션 관련 교육프로그램의 내용을 분석함으 로써 교육내용 프레임웍을 도출하였다. 도출된 교육내용 프레임웍의 타당성을 확보하기 위해 5 학기 이상 공학커 뮤니케이션 교과목을 교육해 본 경험이 있는 공학전공 교수 11명과 공학계열 대학생 95 명을 대상으로 요구분 석을 실시하였다. 전문가와 학습자들의 공학커뮤니케이션 교육과정 내용 구성요소에 대한 중요도-수행도 매트 릭스 분석을 통해 최종 5 개의 영역 18 개의 내용 구성요소가 선정되었다. 학술글쓰기에 4 개, 일반커뮤니케이션 5 개, 취업커뮤니케이션 4개, 직무관련커뮤니케이션 3개, 발표커뮤니케이션 2개의 내용구성요소가 개발되었다. 이 연구의 결과는 전국의 공학계열 대학에서 공학커뮤니케이션 교과목의 교육내용을 구성하는데 있어 실천적 가이드라인을 제공해 주리라 기대된다.

주요어 : 공학커뮤니케이션, 교육내용 구성체계, 요구분석, 중요도-수행도 분석

* 국가평생교육진흥원

** 교신저자, 인하대학교, 미래융합교육원, 조교수 


\section{I . 서론}

현대의 과학기술은 다른 세대와 비교했을 때 상상을 초월할 만큼 빠른 속도로 변화하고 있으 며, 이러한 변화에 대처하기 위해 공학 인재의 양성방향도 달라지고 있다. 공학교육의 가장 두드 러진 변화는 개별 분야의 전문성을 강조하던 경향에서 다양한 분야의 전문가와 명확하게 의사 소통하고 효율적으로 협력할 수 있는 능력을 신장시키는데 관심을 기울이고 있다. 이러한 인재 상의 변화에 기반하여 공학교육인증프로그램에서 요구하는 커뮤니케이션 관련 학습성과를 달 성할 수 있는 교육프로그램이 “공학커뮤니케이션" 교과목이라 할 수 있다 (이효녕 외, 2009; 이희정, 2009).

과학 기술의 세계화가 급속히 진행되고 학문간 융합과 협력이 활발하게 이루어지는 최근의 동향에 비추어 볼 때 국내 및 국제적 상황에서 자신의 연구결과를 발표, 공유, 그리고 확산시키 는 능력과 다른 분야의 과학기술을 수용, 이해, 그리고 해석하는 일련의 커뮤니케이션 능력은 공학자들의 핵심능력으로 자리매김하고 있다 (신선경, 2009). 예를 들어, 어떤 과학기술자가 훌 륭한 연구를 수행하여 획기적인 제품을 개발하였더라도 이를 납득할 만한 논리적인 방식으로 설명하지 못한다면 그 제품의 가치를 충분히 인정받기 어려울 것이며, 아무리 훌륭한 연구주제 를 가지고 있다 하더라도 논리적이지 못한 제안서로 상대방의 협조를 구하기란 어려운 일이다. 따라서 자신의 의견을 상대방이 쉽게 이해하고 수용할 수 있도록 만드는 공학 전공자들의 커뮤 니케이션 능력은 매우 중요한 능력으로 강조되고 있다.

그러나 공학계열 대학생들은 스스로 자신의 커뮤니케이션 능력이 상당히 부족하다고 느끼고 있으며, 이러한 능력의 부족으로 학업을 수행하는데 상당한 어려움을 겪고 있는 것으로 보고되 고 있다. 커뮤니케이션의 한 유형으로 대표될 수 있는 공학 계열 대학생들의 글쓰기 교육에 대한 인식을 조사한 이효녕 외 (2009)에 의하면, 설문에 응답한 학부생 $64.1 \%$, 대학원생 $85.9 \%$ 가 글쓰 기 능력의 부족으로 대학 학습과정에 어려움을 겪고 있다고 응답하였다. 구체적으로는 실험보고 서나 논문 작성 등 학문적 글쓰기 $(78 \%)$, 제품설명서, 제안서, 프레젠테이션을 위한 글쓰기 $(81.7 \%)$, 그리고 그림이나 도표를 쉽게 설명하고 작성하는 글쓰기 $(86.1 \%)$ 에 어려움을 많이 겪고 있는 것으로 조사되었다. 한편, 공학커뮤니케이션 관련 교과목이 운영된다 할지라도 공학이라는 학문의 특성과 졸업 후 학생들이 활동할 직업분야에서 요구하는 커뮤니케이션 능력 등에 대한 충분한 분석 없이 교수자의 직관에 의한 교육은 학생들이 해당 교과목을 통해 달성할 수 있는 학습목표가 제한적일 수밖에 없다. 즉, 공학계열 대학생들의 커뮤니케이션 능력이 공학교육에 있어서 중요한 부분이고 전공교육과 졸업 이후 직업 활동에도 매우 중요한 영향을 미치는 핵심 요인이라면, 학습자의 특성과 요구, 전공과 직업 활동과 연계된 사회적 특성과 요구 등에 부합하 는 교육목표와 교육과정의 구성체계가 수립되어야 함에도 불구하고 이에 대한 연구가 미흡하였다. 
이에 이 연구의 목적은 과학기술분야의 시대적 변화, 대학에서의 공학교육의 변화에 맞추어 공학자가 갖추어야할 핵심역량으로써 공학커뮤니케이션 능력을 향상시킬 수 있는 교육과정 구 성체계를 개발하는데 있다. 이를 위하여 공과계열의 특성에 기반한 대학생 및 교수자들의 요구 를 분석하여 공학커뮤니케이션 교육프로그램의 교육과정을 개발하고자 한다. 이러한 연구결과 는 공과계열 대학생들의 과학기술 관련 연구와 활동에 필요한 커뮤니케이션 능력을 향상시킬 수 있는 효과적인 교육프로그램을 개발하고 운영하는데 실천적 가이드라인을 제시해 줄 수 있 으리라 기대된다.

\section{ㅍ. 선행연구 탐색}

\section{1. 공학커뮤니케이션의 개념 및 중요성}

커뮤니케이션이란 음성 및 문자로 이루어지는 언어적.비언어적 상징을 통한 정보와 감정 등의 교류를 의미한다(오정숙, 2010). 공학커뮤니케이션은 직업세계에서 사용되는 문자와 구두 커뮤 니케이션을 일컫는 일반적인 용어로서 비즈니스, 산업사회 뿐만 아니라 기타 전문적인 근로현장 에서 요구되는 구성원 간 효과적인 의사소통을 의미한다(Pfeiffer \& Adkins, 2010). 특히 과학, 공학, 보건과학 등의 분야에서 널리 쓰이며 업무상 그리고 업무 외적으로 기록된 문서도 포함한 다. Dobrin, Keller 그리고 Weisser (2008)는 공학커뮤니케이션은 전문가로 활동하면서 접하게 되는 복잡하고 정교한 문제, 이슈, 주제에 대한 커뮤니케이션으로 정의하였으며, 청중으로 하여 금 정보를 가시화하고 이해하도록 함으로써 정보에 근거한 윤리적인 결정을 내리도록 하고 적 절하고 안전한 행동을 취하도록 하는 역할을 한다고 설명하였다.

커뮤니케이션은 정보와 감정 등을 만들어내는 송신자와 그것을 받는 수신자, 정보와 감정이 언어적 또는 비언어적 상징으로 표현되는 메시지, 그리고 그 메시지가 전달되는 통로인 채널 등 다양한 요소가 개입되므로 의도치 않게 커뮤니케이션이 왜곡되거나 단절되는 현상이 나타나곤 한다. 따라서 효과적인 커뮤니케이션을 위해서는 보편적으로 갖추어야 할 역량들이 있다 (Makay, Davis, \& Fanning, 1995). 커뮤니케이션 역량에 대한 중요성은 많은 선행연구들에서 확인할 수 있다. 20세기 말 미국에서는 모든 학생들이 반드시 갖추어야 할 역량으로 말하기 및 듣기와 같은 기초적 커뮤니케이션 능력뿐만 아니라 다양한 배경을 가진 사람들과 함께 일하는 능력과 같은 고차원적 커뮤니케이션 능력을 제시하였다(SCANS, 1991). 영국, 캐나다, 호주에서 도 학생들이 갖추어야 할 핵심역량으로 커뮤니케이션 역량을 제시해 왔다(장욱희, 이상호, 2009; Johnstone \& Warson, 2004). 
이와 같이 일반적인 학생들에게도 핵심역량, 직무기초역량으로 커뮤니케이션 역량의 중요성 이 강조되어 왔지만 특히 공학계열 학생들에 대한 커뮤니케이션의 중요성은 다른 계열 학생들 과 비교했을 때 더 강조되어 왔다. 왜냐하면, 공과계열 학생들의 의사소통 능력 수준이 다른 계 열 학생들에 비해 상대적으로 낮기 때문이다(Lee \& Lunsford, 2007). 경험적인 연구결과에 기반 하여 보았을 때, 공학계열 대학생들의 의사소통 불안 수준은 평균 68.98 점이었으나 일반 대학생 들의 의사소통 불안 수준의 평균은 65.6점이었다(Burroughs, Marie, \& McCroskey, 2003; P'Rayan \& Shetty, 2008). 이에 따라 공학계열 학생들을 대상으로 한 커뮤니케이션 교육프로그 램의 필요성이 제기되고 있으며 특히, 신입생부터 학생들의 커뮤니케이션 교육에 참여시킴으로 써 의사소통능력의 중요성에 대한 학생들의 인식을 고취시키고 기초능력을 함양해야 한다는 요 구가 증가하고 있다(Kolmos \& Holgaard, 2008; Lee \& Lunsford, 2007; P'Rayan \& Shetty, 2008).

공학커뮤니케이션의 중요성이 교육과정에 적극적으로 반영된 것은 미국공학기술인증원 (ABET: Accreditation Board for Engineering and Technology)에서 공학계열 학생들이 졸업시 점까지 갖추어야 능력과 자질로써 커뮤니케이션 능력을 제시한 것에서 기인한다. 국내에서도 한 국공학교육인증원(Accreditation Board for Engineering Education of Korea, ABEEK)이 공학교 육인증 기준을 채택하면서 이공계 학생들의 커뮤니케이션 역량 함양을 위한 제도적 변화와 연 구를 시도해 오고 있다(권성규, 2010). 공학교육인증제도로 인해 글쓰기를 필두로 한 이공계 학 생들의 커뮤니케이션 관련 다양한 교과목과 교육프로그램 개발 연구가 수행되어 왔다. 공대생을 위한 글쓰기 교과목의 개설과 교재개발 연구 (권성규, 2010; 최상민, 2009; 이희정, 2009; 신선경, 2009)와 이공계 대학생을 대상으로 한 글쓰기 교수법에 대한 연구(오윤선, 2006) 등이 그 사례이 다. 특히, 공학교육인증에서 졸업시까지 학생들이 달성해야 하는 10 개의 학습성과 중 하나인 “다양한 환경에서 효과적으로 의사소통할 수 있는 능력 (KEC 2015)"을 달성시키기 위한 최적의 교과목으로 공학커뮤니케이션 교과목을 운영하고 있는 공학계열 대학이 많다.

\section{2. 국내외 공학커뮤니케이션 교과목 내용분석}

일반 대학생들을 위한 커뮤니케이션 교육과정 개발 연구에서, 오정숙(2010)은 우니라나 대학 생에게 미래사회에 필요한 커뮤니케이션 역량으로 상황에 맞는 커뮤니케이션 능력, 창조적 커뮤 니케이션 능력, 대상에 맞는 커뮤니케이션 능력, 전달방법에 따른 커뮤니케이션 능력, 공감형성 능력의 5 가지 역량으로 구분하여 제시하였다. 신선경(2009)은 공학 전공자를 위한 의사소통 교 육에서 다루어야 할 내용으로 다음의 7 가지 항목을 정리하여 제시하였다. 첫째, 자료를 이해하 고 분석하여 정리할 수 있는 능력, 둘째, 자신의 실험 혹은 설계의 각 단계를 설명하고 정리할 수 있는 능력, 셋째, 사회적 이슈를 이해하고 과학기술의 사회적 필요를 파악할 수 있는 능력, 
넷째, 세계적 표준에 맞추어 문서를 작성하고 발표할 수 있는 능력, 다섯째, 다학제적 상황을 이 해하고 타전공자나 일반인에게 전공지식을 이해하기 쉽게 전달할 수 있는 능력, 여섯째, 세계문 화에 대한 이해와 국제적으로 협동할 수 있는 능력, 일곱째, 글쓰기의 윤리를 이해하고 참고자료 를 정해진 규칙에 따라 제시할 수 있는 능력이다. 이와 같이 부분적으로 커뮤니케이션 교육과정 구성에 대한 시사점을 제공해 주는 연구를 수행한 선행연구들이 일부 있었으나 제시한 연구결 과가 한 학기의 교과목의 내용을 구성하는데 있어 구체적인 가이드라인을 제공해 주지 못하고 있다.

이에 공학커뮤니케이션 교과목의 내용구성체계를 개발하기 위해 국내외 대학에서 운영되고 있는 공학커뮤니케이션 교과목을 분석하였다. 국내의 경우 수도권에 위치한 20여개의 대학을 분 석의 대상으로 정하였으나 대학마다 글쓰기와 의사소통을 분리하여 운영하는 경우도 있어 교과 목명에 글쓰기와 의사소통을 모두 포함하고 있는 5 개 대학(건국대, 고려대, 동국대, 인하대, 한양 대)의 공학커뮤니케이션 관련 교과목을 분석하였다. 국외의 경우에는 스탠포드대학(Stanford University), 퍼듀대학(Purdue University), 텍사스대학(University of Texas at Austin)에서 운영 하고 있는 기술커뮤니케이션(Technical Communication)이라는 교육프로그램을 분석하였다. 분 석자료는 각 대학의 해당 교과목의 강의계획서이다.

국내외에서 운영되고 있는 공학커뮤니케이션 교과목의 내용을 분석한 결과, 학교마다 세부 내용에는 차이가 있었으나 대체로 취업준비 커뮤니케이션, 의사결정 및 의견조율, 발표 커뮤니 케이션, 목적에 부합하는 글쓰기, 직무수행 글쓰기, 학술적 글쓰기의 여섯 영역을 다루고 있는 것으로 확인되었다. 구체적인 분석결과는 <표 $1>$ 과 같다. 


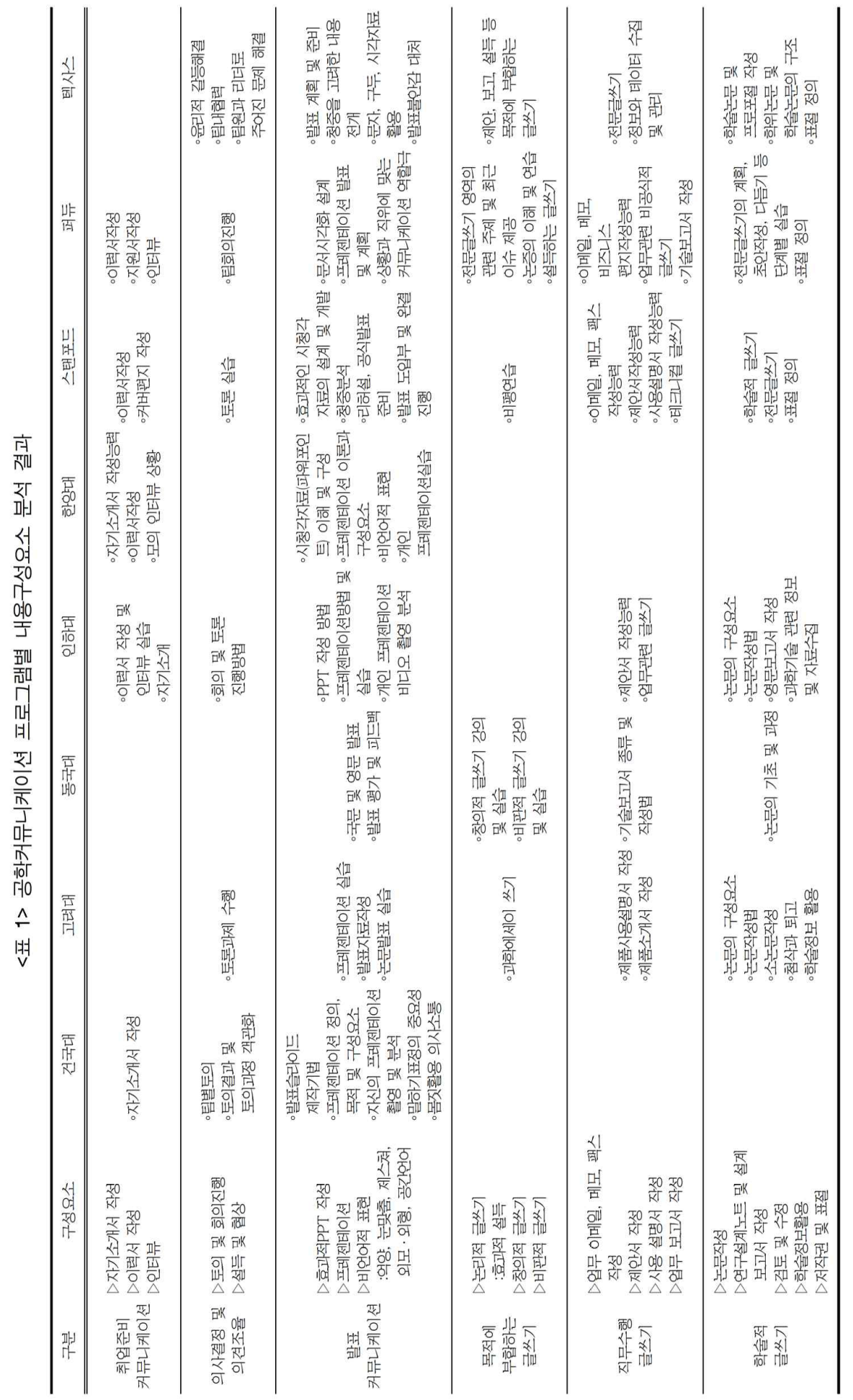




\section{III. 공학커뮤니케이션 교육프로그램에 대한 요구분석}

\section{1. 연구대상}

공학커뮤니케이션 교육과정에 대한 요구분석은 공학커뮤니케이션 강의를 담당하고 있는 전 문가와 공학계열 대학생들을 대상으로 실시하였다. 공학커뮤니케이션 강의를 담당하고 있는 전 문가는 $\mathrm{A}$ 대학교 교수 11 명 (남 10 명, 여 1명)이었다. 이들의 평균 연령은 42.55세 $(\mathrm{SD}=7.13$ )였으 며, 전공 강의경력은 평균 10.32 년 $(\mathrm{SD}=6.54)$, 공학커뮤니케이션 강의경력은 평균 2.74 년 $(\mathrm{SD}=1.87)$ 이었다. 공학계열 학생들은 동일한 대학의 $1-4$ 학년 대학생 95명 (남 80 명, 여 15명)이 참여하였다. 1 3학년 학생들은 학년별 100명, 그리고 4학년 학생들은 500 명을 무작위 추출하여 e-survey 시스템을 통해 일주일동안 설문응답을 요청하였고 이에 응답한 학생들은 총 103명이 었으나 결측치가 있는 8 명의 자료를 제외한 총 95 명의 자료를 분석의 대상으로 하였다. 이들의 평균 연령은 23.13세 ( $\mathrm{SD}=2.50)$ 이었으며, 학년별로는 1학년 16명 $(16.8 \%)$, 2학년 16명(16.8\%), 3학 년 11명(11.6\%), 그리고 4학년 52명(54.7\%) 이었다. 4학년을 보다 많은 비중으로 조사한 이유는 대학교육의 경험이 보다 풍부하기 때문에 보다 교육과정에 대한 실제적인 필요를 제시할 수 있 을 뿐만 아니라 대학생들의 공학커뮤니케이션 능력에 대한 현 수준에 대한 인식을 보다 구체적 으로 측정할 수 있기 때문이었다.

\section{2. 연구도구}

공학커뮤니케이션 교육과정에 대한 요구를 분석하기 위해 공학커뮤니케이션 교육 전문가용 과 공과계열 대학생용 2 가지 설문도구가 개발되었다. 전문가용 설문도구는 총 21 개의 문항으로 구성되었다. 공학커뮤니케이션 교과목의 필요성을 묻는 1 개 문항과 선행문헌 분석 및 국내외 공 학커뮤니케이션 교육과정 사례 분석을 통해 도출된 이론적 프레임웍을 근거로 하여(<표 $1>$ 참 조) 일반적으로 중요도-수행도 분석연구에서 활용되고 있는 연구도구를 참조하여 20개의 설문 문항이 개발되었다(진성희, 김태현, 2010). 20개의 설문문항은 2가지 영역으로 구성하였는데 다 음 <표 2>와 같이 공학커뮤니케이션 교육내용으로써의 중요도와 현 공학계열 대학생들의 해당 능력 수행수준에 대한 인지정도를 물어보았다. 대학생용 설문도구는 전문가용과 동일한 21문항 에 공학커뮤니케이션 교과목 수강경험을 묻는 1 개 문항을 추가로 개발하였다. 전문가용과 마찬 가지로 공학커뮤니케이션 교육과정 내용에 대한 중요도와 해당 교육내용에 대한 자신의 능력 수준에 대한 수행도를 묻는 문항을 중심으로 설문이 구성되었다.

연구도구의 내용 타당도를 검증하기 위해 공학커뮤니케이션 교육을 담당하고 있는 전문가 2 
인을 대상으로 내용 타당도 검사를 실시하였고, 그 결과를 반영하여 문항을 수정.보완하였다. 각 대상 및 각 영역별 설문결과의 신뢰도를 살펴보면, 전문가용 설문도구의 신뢰도 Cronbach $\alpha$ 는 중요도 .92, 학생들의 수행도 .95였으며, 대학생용 설문도구의 신뢰도 Cronbach $\alpha$ 는 중요도 .94, 수행도 .93으로 연구도구의 신뢰도가 상당히 양호한 것으로 나타났다.

<표 2> 전문가 및 대학생용 설문도구 예시

\begin{tabular}{|c|c|c|c|c|c|c|c|c|c|c|}
\hline \multirow{2}{*}{$\begin{array}{c}\text { 공학커뮤니케이션 } \\
\text { 내용구성요소 }\end{array}$} & \multicolumn{5}{|c|}{ 필요한 정도 } & \multicolumn{5}{|c|}{$\begin{array}{l}\text { 현 학생의 수준(전문가용) } \\
\text { 현재 자신의 수행 } \\
\text { 수준(대학생용) }\end{array}$} \\
\hline & $\begin{array}{c}5 \\
\text { 매우 } \\
\text { 필요 }\end{array}$ & $\begin{array}{c}4 \\
\text { 필요 }\end{array}$ & $\begin{array}{c}3 \\
\text { 보통 }\end{array}$ & $\begin{array}{l}2 \\
\text { 필요 } \\
\text { 없음 }\end{array}$ & $\begin{array}{l}1 \\
\text { 매우 } \\
\text { 필요 } \\
\text { 없음 }\end{array}$ & $\begin{array}{l}5 \\
\text { 매우 } \\
\text { 높음 }\end{array}$ & $\begin{array}{c}4 \\
\text { 높음 }\end{array}$ & $\begin{array}{c}3 \\
\text { 보통 }\end{array}$ & $\begin{array}{c}2 \\
\text { 낮음 }\end{array}$ & $\begin{array}{c}1 \\
\text { 매우 } \\
\text { 낮음 }\end{array}$ \\
\hline $\begin{array}{l}\text { 자기소개서 작성능력: 고용주에게 채용 } \\
\text { 직종 및 직급과 관련하여 자신의 자격 } \\
\text { 요건 및 배경을 설명함으로써 자신이 } \\
\text { 적임자라는 것을 글로 표현하는 능력 }\end{array}$ & 5 & 4 & 3 & 2 & 1 & 5 & 4 & 3 & 2 & 1 \\
\hline $\begin{array}{l}\text { 이력서 작성능력: 자신이 누구인지를 } \\
\text { 간결하게 설명하기 위하여 교육의 정 } \\
\text { 도, 채용직종 및 직급과 관련된 전문적 } \\
\text { 인 경력, 대외 활동 경력 등의 배경을 } \\
\text { 글로 표현하는 능력 }\end{array}$ & 5 & 4 & 3 & 2 & 1 & 5 & 4 & 3 & 2 & 1 \\
\hline $\begin{array}{l}\text { 인터뷰 능력: 고용주와 면대면 질의응 } \\
\text { 답을 통해 자신의 잠재능력, 책임감, } \\
\text { 창의적 사고력, 업무 추진력, 대인관계, } \\
\text { 성격 등을 짧은 시간 내에 효과적으로 } \\
\text { 호소하는 능력 }\end{array}$ & 5 & 4 & 3 & 2 & 1 & 5 & 4 & 3 & 2 & 1 \\
\hline
\end{tabular}

\section{3. 자료분석 방법 및 분석도구}

공학커뮤니케이션 교육 전문가와 공학계열 대학생들의 공학커뮤니케이션 교육내용에 대한 중요도와 수행도의 응답 결과를 바탕으로 교육과정 구성체계를 도출하였다. 이를 위해 첫째, 설문에 응답한 집단 간(전문가와 대학생)의 교육내용에 대한 인식차이와 대학생 중에서 공학커 뮤니케이션 교육을 받은 경험이 있는 집단과 그렇지 않은 집단 간의 인식차이를 독립표본 $\mathrm{t}$-검 증(Independent samples t-test)을 실시하였다. 둘째, 대학생들이 중요하다고 생각되는 내용을 중 심으로 어떠한 교육내용을 중요시하는지에 대한 요인분석을 실시하였다. 셋째, 도출된 요인을 중심으로 전문가와 대학생들의 중요도와 수행도를 중심으로 교육과정에 포함되어야 할 핵심내 용과 일반내용, 그리고 불필요한 내용 등을 분석하였다. 이를 위해 Martilla와 James(1977)가 제 
안한 바에 따라 중요도-수행도 매트릭스를 작성하였다. 매트릭스에서 평균을 중심으로 구성요소 의 중요도는 높고 수행도가 낮으면 관련 교육을 제공해야 하는 핵심 구성요소, 구성요소의 중요 도가 낮고 수행도도 역시 낮으면 교육프로그램으로 제공하지 않아도 되는 구성요소, 중요도와 수행도가 모두 높은 구성요소는 유지시키기 위해 교육프로그램으로 제공해도 좋을 구성요소, 중 요도는 낮으나 수행도가 높은 구성요소는 교육프로그램으로 제공하지 않아도 되는 구성요소로 해석된다. 넷째, 전문가와 대학생들의 중요도와 수행도를 중심으로 우선적으로 개발되어야 할 내용의 우순순위를 도출하였다. 마지막으로, 공학커뮤니케이션 교육프로그램을 위한 최종 내용 구성체계가 개발되었다.

\section{4. 요구분석 결과}

1) 공학커뮤니케이션 교육에 대한 요구

공학커뮤니케이션 교육의 필요성에 대해서는 전문가집단과 대학생집단 모두 평균수준이상으 로 그 필요성을 인식하고 있는 것으로 나타났다(전문가: 평균=5.00, 표준편차=.00; 대학생: 평균 $=3.74$, 표준편차=.97). 특히 이 연구에 참여한 공학커뮤니케이션 교육을 담당하는 전문가 전원은 매우 필요하다고 응답하였다. 대학생의 경우 공학커뮤니케이션 교육 경험 유무에 따라 필요성 인식에 차이가 있는지를 확인해 본 결과, 유의수준 $\mathrm{p}<.01$ 에서 통계적으로 유의미하게 공학커뮤 니케이션 교육을 받은 대학생들이 그 필요성을 보다 높게 인식하고 있는 것으로 확인되었다(경 험 유 $(\mathrm{n}=54)$ : 평균=3.96, 표준편차=.95; 경험 무 $(\mathrm{n}=41)$ : 평균=3.46, 표준편차=.95, $\mathrm{t}=2.53)$. 다시 말해서, 공학커뮤니케이션 교육에 대한 필요성은 전문가집단과 대학생집단 모두 인식하고 있었 으며, 대학생보다는 전문가들이, 교육을 받은 대학생이 그렇지 않은 학생보다 그 필요성을 높게 인식하고 있는 것으로 드러났다.

\section{2) 공학커뮤니케이션 교육내용 구성요인}

공학커뮤니케이션 교육내용을 선정하기 위하여 탐색적 요인분석을 실시하였다. 이를 위해 선 행문헌 분석 및 국내외 대학의 사례 분석을 통해 구성된 20개 내용들의 적절성 여부를 판단하기 위하여 각 요소들의 정규분포 가정 및 신뢰도 계수를 확인하였다. Curran, West와 Finch (1996) 에 따르면 정규분포의 지표인 왜도는 2이하, 첨도는 7이하의 기준을 제시하고 있는데, <표 3>에 제시된 바와 같이 왜도는 -1.89에서 - .40 , 첨도는 -.66에서 4.36으로 나타나 이러한 기준을 모두 충족하는 것으로 확인되었다. 또한 각 요소들의 신뢰도 계수 Cronbach $\alpha$ 를 분석한 결과 0.940 
에서 0.943 으로 나타나 매우 신뢰할 수 있는 것으로 확인되었다.

<표 3> 공학커뮤니케이션 교육과정 내용구성요소의 기술통계 분석

\begin{tabular}{llllll}
\hline \multicolumn{1}{c}{ 교육과정 내용 구성요소 } & 평균 & $\begin{array}{c}\text { 표준 } \\
\text { 편차 }\end{array}$ & 왜도 & 첨도 & 신뢰도 \\
\hline 1. 자기소개서 작성능력 & 4.47 & 0.79 & -1.89 & 4.36 & .942 \\
\hline 2. 이력서 작성능력 & 4.33 & 0.91 & -1.62 & 2.91 & .942 \\
\hline 3. 인터뷰 능력 & 4.12 & 1.00 & -1.07 & 0.73 & .942 \\
\hline 4. 토의 및 회의진행능력 & 4.11 & 0.86 & -0.64 & -0.37 & .943 \\
\hline 5. 설득 및 협상능력 & 4.31 & 0.84 & -1.10 & 0.57 & .942 \\
\hline 6. 효과적 PPT작성능력 & 4.37 & 0.91 & -1.53 & 1.94 & .943 \\
\hline 7. 프레젠테이션능력 & 4.49 & 0.75 & -1.43 & 1.47 & .942 \\
\hline 8. 비언어적 표현 능력 & 4.10 & 0.92 & -0.64 & -0.64 & .941 \\
\hline 9. 논리적 글쓰기 능력 & 4.13 & 0.93 & -0.86 & -0.16 & .940 \\
\hline 10. 창의적 글쓰기 능력 & 4.00 & 0.92 & -0.79 & 0.36 & .942 \\
\hline 11. 비판적 글쓰기 능력 & 4.08 & 0.81 & -0.40 & -0.66 & .941 \\
\hline 12. 업무 이메일, 메모, 팩스 작성능력 & 3.79 & 1.02 & -0.73 & 0.27 & .942 \\
\hline 13. 제안서 작성능력 & 4.11 & 0.87 & -0.85 & 0.74 & .941 \\
\hline 14. 사용 설명서 작성능력 & 3.58 & 1.08 & -0.41 & -0.50 & .942 \\
\hline 15. 업무 보고서 작성능력 & 3.90 & 1.00 & -0.61 & -0.35 & .942 \\
\hline 16. 논문작성 능력 & 4.02 & 0.97 & -0.88 & 0.25 & .941 \\
\hline 17. 연구 설계노트 및 설계 보고서 작성능력 & 3.96 & 0.86 & -0.57 & 0.36 & .941 \\
\hline 18. 검토 및 수정 & 4.71 & 1.09 & -0.57 & -0.36 & .941 \\
\hline 19. 학술정보 활용능력 & 4.02 & 1.01 & -0.90 & 0.34 & .941 \\
\hline 20. 저작권 및 표절에 대한 이해능력 & 0.95 & -0.94 & 0.06 & .941 \\
\hline & & & & \\
\hline
\end{tabular}

앞서 분석된 교육내용의 구성요소들이 모두 요인분석을 위해 타당한 변인임이 확인되었다. 탐색적 요인분석을 위한 자료의 적합성 여부를 확인하기 위하여 $\mathrm{KMO}$ 와 Bartlett 구형성 검정을 우선적으로 실시하였다. $\mathrm{KMO}$ 값은 .864 이고, Bartlett 구형성 검정값 $\chi^{2}=1031.158$ 이며, 이러한 검정값들의 유의수준이 $\mathrm{p}<.01$ 에서 유의하므로 본 연구에 사용되는 20개의 요소들은 탐색적 요 인분석을 하는데 적합하다는 것이 재확인되었다. 요인분석은 변수 간에 적어도 하나 이상의 다 른 항목과 높은 상관관계를 가지고 있어야 하므로 모든 항목에 대한 상관관계행렬을 검토하는 주성분분석기법(Principle components)을 이용하여 각 요인을 추출하였고, 이를 직교회전방법 
(Varimax method)이 적용되었다. 요인분석결과 설명력이 떨어지는 문항(.400 이하)이 없어 총 20 개 내용 구성요소가 5개 영역으로 구분되어 나타났으며 5개 요인에 대한 전체 설명력은 $71.69 \%$ 로 나타났다. 보다 구체적인 결과는 <표 $4>$ 에 제시되었다. 각 요인을 구성하는 하위 내용 요소들의 특성을 반영하여 제 1 요인은 학술적 글쓰기, 제 2 요인은 일반커뮤니케이션, 제 3 요인은 취업커뮤니케이션, 제 4 요인은 직무관련커뮤니케이션, 제5요인은 발표커뮤니케이션으로 명명하 였다.

<표 4> 공학커뮤니케이션 교육과정 내용구성요소에 대한 요인분석 결과

\begin{tabular}{|c|c|c|c|c|c|}
\hline 교육과정 내용 구성요소 & 요인1 & 요인2 & 요인3 & 요인4 & 요인5 \\
\hline 논문작성 능력 & .776 & .156 & .046 & .098 & .359 \\
\hline 연구 설계노트 및 설계 보고서 작성능력 & .752 & .077 & .301 & .003 & .225 \\
\hline 학술정보 활용능력 & .693 & .240 & .264 & .084 & .196 \\
\hline 검토 및 수정 & .682 & .201 & .277 & .300 & -.066 \\
\hline 저작권 및 표절에 대한 이해능력 & .657 & .311 & .035 & .284 & -.026 \\
\hline 논리적 글쓰기 능력 & .267 & .793 & .162 & .113 & -.016 \\
\hline 창의적 글쓰기 능력 & -.100 & .770 & .173 & .131 & .204 \\
\hline 비판적 글쓰기 능력 & .290 & .714 & .126 & .055 & .264 \\
\hline 토의 및 회의진행능력 & .413 & .712 & .175 & .141 & .250 \\
\hline 비언어적 표현 능력 & .379 & .646 & .079 & .246 & .192 \\
\hline 자기소개서 작성능력 & .063 & .062 & .883 & .144 & .165 \\
\hline 이력서 작성능력 & .181 & .108 & .878 & .095 & .079 \\
\hline 업무 이메일, 메모, 팩스 작성능력 & .245 & .173 & .679 & .184 & -.035 \\
\hline 인터뷰 능력 & .155 & .275 & .642 & .271 & .076 \\
\hline 업무 보고서 작성능력 & .240 & .016 & .198 & .825 & .122 \\
\hline 설득 및 협상능력 & -.087 & .274 & .209 & .694 & .382 \\
\hline 제안서 작성능력 & .289 & .295 & .247 & .680 & -.059 \\
\hline 사용 설명서 작성능력 & .211 & .116 & .532 & .538 & -.111 \\
\hline 프레젠테이션능력 & .152 & .285 & .111 & .105 & .826 \\
\hline 효과적 PPT작성능력 & .284 & .200 & .032 & .065 & .826 \\
\hline 고유치 & 8.134 & 2.250 & 1.537 & 1.264 & 1.155 \\
\hline 설명변량(\%) & 17.215 & 16.494 & 16.067 & 11.835 & 10.081 \\
\hline 누적변량(\%) & 17.215 & 33.710 & 49.777 & 61.612 & 71.694 \\
\hline
\end{tabular}


3) 공학커뮤니케이션 교육내용 구성요소에 대한 중요도-수행도 분석

요인분석을 통해 확인된 공학커뮤니케이션 교육과정 내용구성요소에 대해 전문가와 대학생 을 대상으로 중요도 및 현 대학생들의 수행수준에 대한 인식을 조사하였다. 구체적인 분석결과 는 다음 <표 $5>$ 와 같다.

<표 5> 공학커뮤니케이션 교육과정 내용구성요소에 대한 중요도-수행도 분석 결과

\begin{tabular}{|c|c|c|c|c|c|c|c|c|c|}
\hline \multirow{3}{*}{ 영역 } & \multirow{3}{*}{ 교육과정 내용 구성요소 } & \multicolumn{4}{|c|}{ 전문가 } & \multicolumn{4}{|c|}{ 대학생 } \\
\hline & & \multicolumn{2}{|c|}{ 중요도 } & \multicolumn{2}{|c|}{ 수행도 } & \multicolumn{2}{|c|}{ 중요도 } & \multicolumn{2}{|c|}{ 수행도 } \\
\hline & & 평균 & $\begin{array}{l}\text { 표준 } \\
\text { 편차 }\end{array}$ & 평균 & $\begin{array}{l}\text { 표준 } \\
\text { 편차 }\end{array}$ & 평균 & $\begin{array}{l}\text { 표준 } \\
\text { 편차 }\end{array}$ & 평균 & $\begin{array}{l}\text { 표준 } \\
\text { 편차 }\end{array}$ \\
\hline \multirow{5}{*}{$\begin{array}{l}\text { 학술 } \\
\text { 글쓰기 }\end{array}$} & 1.논문작성 능력 & 3.82 & 0.87 & 2.00 & 0.89 & 4.02 & 0.97 & 3.04 & 1.02 \\
\hline & $\begin{array}{l}\text { 2.연구 설계노트 및 설계 } \\
\text { 보고서 작성능력 }\end{array}$ & 4.00 & 0.89 & 2.18 & 0.75 & 3.96 & 0.86 & 3.02 & 0.87 \\
\hline & 3.학술정보 활용능력 & 4.55 & 0.52 & 2.64 & 1.03 & 4.11 & 0.95 & 3.30 & 0.97 \\
\hline & 4.검토 및 수정 & 3.00 & 1.34 & 1.45 & 0.69 & 3.71 & 1.09 & 2.78 & 1.02 \\
\hline & $\begin{array}{l}\text { 5.저작권 및 표절에 대한 } \\
\text { 이해능력 }\end{array}$ & 3.82 & 0.98 & 2.82 & 0.87 & 4.02 & 1.01 & 3.21 & 0.90 \\
\hline \multirow{5}{*}{$\begin{array}{c}\text { 일반 } \\
\text { 커뮤니케이션 }\end{array}$} & 6.논리적 글쓰기 능력 & 4.64 & 0.67 & 1.82 & 0.75 & 4.13 & 0.93 & 3.24 & 0.98 \\
\hline & 7.창의적 글쓰기 능력 & 4.36 & 0.67 & 1.91 & 0.83 & 4.00 & 0.92 & 3.10 & 1.07 \\
\hline & 8.비판적 글쓰기 능력 & 3.91 & 1.14 & 2.00 & 0.89 & 4.08 & 0.81 & 3.31 & 1.00 \\
\hline & 9.토의 및 회의진행능력 & 4.55 & 0.93 & 2.27 & 0.65 & 4.11 & 0.86 & 3.25 & 1.07 \\
\hline & 10.비언어적 표현 능력 & 4.64 & 0.67 & 2.09 & 0.83 & 4.10 & 0.92 & 3.38 & 1.05 \\
\hline \multirow{4}{*}{$\begin{array}{c}\text { 취업 } \\
\text { 커뮤니케이션 }\end{array}$} & 11.자기소개서 작성능력 & 4.55 & 0.69 & 2.55 & 0.69 & 4.47 & 0.79 & 3.34 & 0.98 \\
\hline & 12.이력서 작성능력 & 4.36 & 0.81 & 2.45 & 0.69 & 4.33 & 0.91 & 3.20 & 1.01 \\
\hline & $\begin{array}{l}\text { 13.업무 이메일, 메모, } \\
\text { 팩스 작성능력 }\end{array}$ & 4.27 & 0.90 & 2.18 & 0.75 & 3.79 & 1.02 & 3.17 & 0.95 \\
\hline & 14.인터뷰 능력 & 4.36 & 0.67 & 2.18 & 0.87 & 4.12 & 1.00 & 3.29 & 1.08 \\
\hline \multirow{4}{*}{$\begin{array}{c}\text { 직무관련 } \\
\text { 커뮤니케이션 }\end{array}$} & 15.업무 보고서 작성능력 & 4.00 & 0.89 & 1.82 & 0.87 & 3.90 & 1.00 & 3.32 & 0.93 \\
\hline & 16.설득 및 협상능력 & 4.64 & 0.50 & 1.91 & 0.83 & 4.31 & 0.84 & 3.66 & 0.97 \\
\hline & 17.제안서 작성능력 & 4.09 & 0.83 & 1.73 & 0.79 & 4.11 & 0.87 & 3.27 & 0.90 \\
\hline & 18.사용 설명서 작성능력 & 3.36 & 0.92 & 2.00 & 0.89 & 3.58 & 1.08 & 3.05 & 0.95 \\
\hline \multirow{3}{*}{$\begin{array}{c}\text { 발표 } \\
\text { 커뮤니케이션 }\end{array}$} & 19.프레젠테이션능력 & 4.91 & 0.30 & 2.36 & 0.92 & 4.49 & 0.75 & 3.40 & 1.07 \\
\hline & 20.효과적 PPT작성능력 & 5.00 & 0.00 & 2.27 & 0.90 & 4.37 & 0.91 & 3.22 & 1.10 \\
\hline & & 4.24 & & 2.13 & & 4.09 & - & 3.23 & - \\
\hline
\end{tabular}


그 결과 전문가집단의 경우 공학커뮤니케이션 내용구성요소들의 중요도에 대한 전체 평균은 4.24였고 대학생들의 수행도 수준에 대한 인식평균은 2.13으로 상당히 낮았다. 대학생의 경우 각 내용구성요소들의 중요도에 대한 전체 평균은 4.09 로 전문가집단과 마찬가지로 상당수준 그 중 요성을 인식하고 있었고 수행수준에 대한 전체 평균은 3.23으로 나타났다. 즉, 학생들을 가르치 고 있는 교수자들보다 학습자가 자신의 수행수준에 대해 더 높게 평가하고 있는 것으로 나타났 다. 공학커뮤니케이션 교육과정 내용구성요소 중 핵심내용을 선정하기 위해 중요도와 수행도 매 트릭스를 분석하였다. 그 결과는 다음 [그림 1]과 같다.
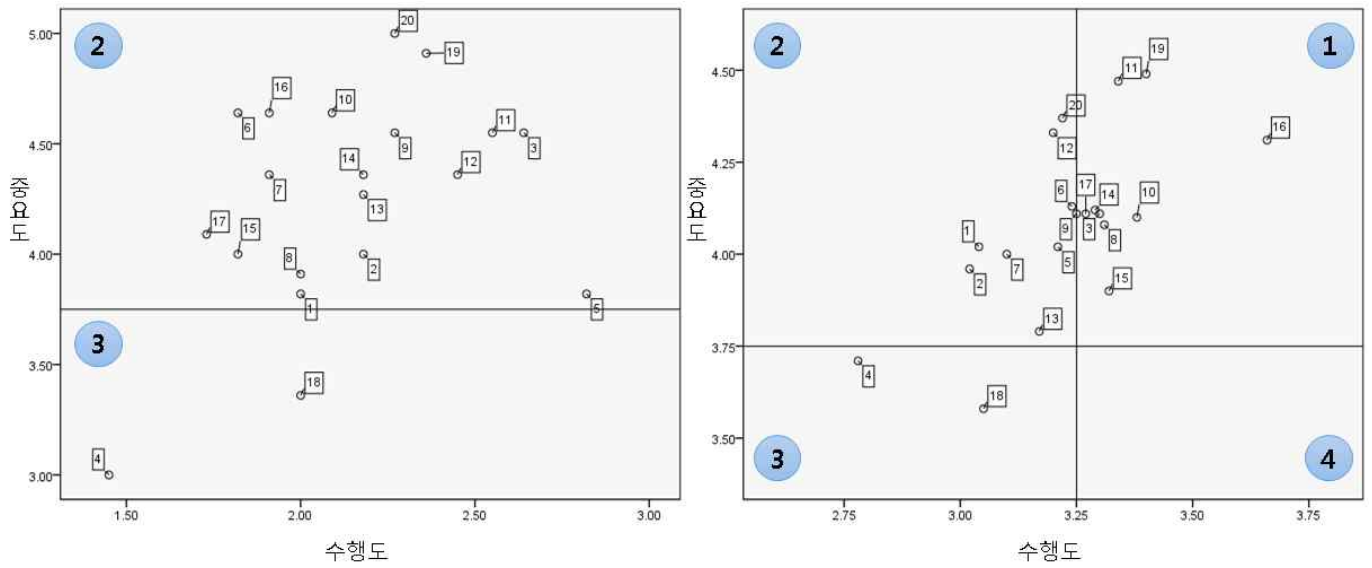

[그림 1] 공학커뮤니케이션 내용구성요소에 대한 중요도-수행도 매트릭스 (좌: 전문가, 우: 대학생)

1.논문작성 능력, 2.연구 설계노트 및 설계 보고서 작성능력, 3.학술정보 활용능력, 4.검토 및 수정, 5.저작권 및 표 절에 대한 이해능력, 6.논리적 글쓰기 능력, 7.창의적 글쓰기 능력, 8.비판적 글쓰기 능력, 9.토의 및 회의진행능력, 10.비언어적 표현 능력, 11 .자기소개서 작성능력, 12. 이력서 작성능력, 13 .업무 이메일, 메모, 팩스 작성능력, 14 .인 터뷰 능력, 15 .업무 보고서 작성능력, 16.설득 및 협상능력, 17.제안서 작성능력, 18.사용 설명서 작성능력, 19.프 레젠테이션능력, 20.효과적 PPT작성능력

[그림 1]의 중요도-수행도 분석 매트릭스를 보면, 중요도는 높으나 수행도가 낮은 2사분면에 있는 내용구성요소가 핵심개발대상이며, 중요도와 수행도가 모두 높은 1 사분면에 위치한 내용 구성요소는 지속개발대상이다. 그리고 중요도가 낮은 3,4 분면에 위치한 내용구성요소들은 개발 이 불필요한 항목으로 볼 수 있다. 전문가집단의 경우에는 모든 내용구성요소에 대해 현 대학생 들의 수행수준이 3.0 이하로 1 사분면과 4 사분면이 없는 것으로 나타났다. 중요도와 수행도를 구 분하는 기준점은 대체로 평균값을 하거나, 연구의 특성을 반영하여 정하는데 이 연구에서는 중 요도는 3.75 , 수행도는 3.25 로 기준점을 설정하여 4 사분면을 구분하였다. 기준점 근방에 있는 요 소들도 핵심개발대상에 포함시켰다.

공학계열 학생들을 위한 최적의 공학커뮤니케이션 교육과정을 개발하기 위해서는 교육을 수 
행하는 교수전문가와 실제 교육을 받은 대학생들의 요구를 분석할 필요가 있다. 이에 교수전문 가와 대학생들의 요구를 보다 면밀하게 분석하기 위해서 각 내용구성요소에 대한 중요도와 수 행도 분석을 실시하였다. 그 결과에 기반하여 교육내용의 우선순위를 결정하면 다음 <표 6>과 같다. 우선순위는 중요도는 높으나 수행도가 상대적으로 낮아 핵심적으로 개발해야 할 내용요 소, 중요도와 수행도가 모두 높아 지속적으로 개발해야 할 내용요소, 중요도가 낮아 개발을 지양 해야 하는 내용요소와 같이 3 단계로 구분하였다.

<표 6> 공학커뮤니케이션 교육과정 내용구성요소 선정 결과

\begin{tabular}{|c|c|c|c|c|c|c|c|c|}
\hline \multirow[b]{2}{*}{ 영역 } & \multirow[b]{2}{*}{ 교육과정 내용 구성요소 } & \multicolumn{3}{|c|}{ 전문가 } & \multicolumn{3}{|c|}{ 대학생 } & \multirow[b]{2}{*}{ 선정 } \\
\hline & & $\begin{array}{l}\text { 핵심 } \\
\text { 개발 }\end{array}$ & $\begin{array}{l}\text { 지속 } \\
\text { 개발 }\end{array}$ & $\begin{array}{l}\text { 개발 } \\
\text { 지양 }\end{array}$ & $\begin{array}{l}\text { 핵심 } \\
\text { 개발 }\end{array}$ & $\begin{array}{l}\text { 지속 } \\
\text { 개발 }\end{array}$ & $\begin{array}{l}\text { 개발 } \\
\text { 지양 }\end{array}$ & \\
\hline \multirow{5}{*}{$\begin{array}{l}\text { 학술 } \\
\text { 글쓰기 }\end{array}$} & 1.논문작성 능력 & - & & & - & & & $\sqrt{ }$ \\
\hline & $\begin{array}{l}\text { 2.연구 설계노트 및 설계 } \\
\text { 보고서 작성능력 }\end{array}$ & - & & & $\bullet$ & & & $\sqrt{ }$ \\
\hline & 3.학술정보 활용능력 & - & & & $(-)$ & & & $\sqrt{ }$ \\
\hline & 4.검토 및 수정 & & & $\triangle$ & & & $\triangle$ & 삭제 \\
\hline & $\begin{array}{l}\text { 5.저작권 및 표절에 대한 } \\
\text { 이해능력 }\end{array}$ & - & & & 0 & & & $\sqrt{ }$ \\
\hline \multirow{5}{*}{$\begin{array}{c}\text { 일반 } \\
\text { 커뮤니케이션 }\end{array}$} & 6.논리적 글쓰기 능력 & - & & & $\bullet$ & & & $\sqrt{ }$ \\
\hline & 7.창의적 글쓰기 능력 & 0 & & & $(-)$ & & & $\sqrt{ }$ \\
\hline & 8.비판적 글쓰기 능력 & - & & & & $\bigcirc$ & & $\sqrt{ }$ \\
\hline & 9.토의 및 회의진행능력 & - & & & $\bullet$ & & & $\sqrt{ }$ \\
\hline & 10.비언어적 표현 능력 & (-) & & & & $\bigcirc$ & & $\sqrt{ }$ \\
\hline \multirow{4}{*}{$\begin{array}{c}\text { 취업 } \\
\text { 커뮤니케이션 }\end{array}$} & 11.자기소개서 작성능력 & (-) & & & & $\bigcirc$ & & $\sqrt{ }$ \\
\hline & 12.이력서 작성능력 & (-) & & & 0 & & & $\sqrt{ }$ \\
\hline & $\begin{array}{l}\text { 13.업무 이메일, 메모, } \\
\text { 팩스 작성능력 }\end{array}$ & - & & & 0 & & & $\sqrt{ }$ \\
\hline & 14.인터뷰 능력 & - & & & (-) & & & $\sqrt{ }$ \\
\hline \multirow{4}{*}{$\begin{array}{c}\text { 직무관련 } \\
\text { 커뮤니케이션 }\end{array}$} & 15.업무 보고서 작성능력 & - & & & & $\bigcirc$ & & $\sqrt{ }$ \\
\hline & 16.설득 및 협상능력 & - & & & & $\bigcirc$ & & $\sqrt{ }$ \\
\hline & 17.제안서 작성능력 & $\bullet$ & & & - & & & $\sqrt{ }$ \\
\hline & 18.사용 설명서 작성능력 & & & $\triangle$ & & & $\triangle$ & 삭제 \\
\hline \multirow{2}{*}{$\begin{array}{c}\text { 발표 } \\
\text { 커뮤니케이션 }\end{array}$} & 19.프레젠테이션능력 & - & & & & $\bigcirc$ & & $\sqrt{ }$ \\
\hline & 20.효과적 PPT작성능력 & - & & & 0 & & & $\sqrt{ }$ \\
\hline
\end{tabular}




\section{IV. 공학커뮤니케이션 교육프로그램 구성체계}

전문가와 대학생 대상의 공학커뮤니케이션 교육에 대한 요구를 분석한 결과 다음 <표 7>과 같이 총 18 개의 내용이 선정되었다. 각 구성요소는 교육내용뿐만 아니라 교육목표로써의 역할도 해야 함으로 각각의 개념을 다음과 같이 정의하였다.

<표 7> 공학커뮤니케이션 교육과정 내용구성요소의 개념

\begin{tabular}{|c|c|c|}
\hline 영역 & 교육과정 내용 구성요소 & 개넘 \\
\hline \multirow{4}{*}{$\begin{array}{l}\text { 학술 } \\
\text { 글쓰기 }\end{array}$} & 1.논문작성 능력 & $\begin{array}{l}\text { 연구자가 수행한 연구결과와 연구자의 견해를 타인이 이 } \\
\text { 해하기 쉽도록 논문의 구성요소와 형식에 맞게 서술하는 } \\
\text { 능력 }\end{array}$ \\
\hline & $\begin{array}{l}\text { 2.연구 설계노트 및 설계 } \\
\text { 보고서 작성능력 }\end{array}$ & $\begin{array}{l}\text { 연구 설계노트를 통해 정보를 공유하고, 연구 설계 보고 } \\
\text { 서 작성을 통해 교과과정에서 배운 전공지식을 활용할 수 } \\
\text { 있는 능력 }\end{array}$ \\
\hline & 3.학술정보 활용능력 & 연구에 필요한 정보를 효과적으로 찾아 활용하는 능력 \\
\hline & $\begin{array}{l}\text { 5.저작권 및 표절에 대한 } \\
\text { 이해능력 }\end{array}$ & $\begin{array}{l}\text { 타인의 논문에 대한 저작권 침해 및 표절 행위, 자신의 } \\
\text { 연구결과의 위조, 변조, 중복게재, 이중게재 등 출판윤리 } \\
\text { 및 연구윤리의 필요성을 이해하는 능력 }\end{array}$ \\
\hline \multirow{5}{*}{$\begin{array}{c}\text { 일반 } \\
\text { 커뮤니케이션 }\end{array}$} & 6.논리적 글쓰기 능력 & $\begin{array}{l}\text { 효과적인 설득하기와 설명하기 전략을 통해 자신의 생각 } \\
\text { 이나 의견을 논리적인 글로 표현하는 능력 }\end{array}$ \\
\hline & 7.창의적 글쓰기 능력 & $\begin{array}{l}\text { 독창적인 문제제기를 통해 지금까지 눈에 띄지 않았던 주 } \\
\text { 제의 글로써 자신의 생각을 표현하는 능력 }\end{array}$ \\
\hline & 8.비판적 글쓰기 능력 & $\begin{array}{l}\text { 주장을 맹목적으로 받아들이지 않고, 논리를 뒷받침하는 } \\
\text { 증거와 예시를 글에 제시하는 능력 }\end{array}$ \\
\hline & 9.토의 및 회의진행능력 & $\begin{array}{l}\text { 회의 또는 토의 참가자의 의견을 존중하면서 회의 또는 } \\
\text { 토의를 주도적으로 진행하고 자신의 의견을 조리있게 제 } \\
\text { 안할 수 있는 능력 }\end{array}$ \\
\hline & 10.비언어적 표현 능력 & $\begin{array}{l}\text { 효과적인 의사소통에 영향을 미치는 비언어적 표현을 효 } \\
\text { 과적으로 하는 능력 }\end{array}$ \\
\hline \multirow{4}{*}{$\begin{array}{c}\text { 취업 } \\
\text { 커뮤니케이션 }\end{array}$} & 11.자기소개서 작성능력 & $\begin{array}{l}\text { 고용주에게 채용직종 및 직급과 관련하여 자신의 자격요 } \\
\text { 건 및 배경을 설명함으로써 자신이 적임자라는 것을 글로 } \\
\text { 표현하는 능력 }\end{array}$ \\
\hline & 12.이력서 작성능력 & $\begin{array}{l}\text { 자신이 누구인지를 간결하게 설명하기 위하여 교육의 정 } \\
\text { 도, 채용직종 및 직급과 관련된 전문적인 경력, 대외 활 } \\
\text { 동 경력 등의 배경을 글로 표현하는 능력 }\end{array}$ \\
\hline & $\begin{array}{l}\text { 13.업무 이메일, 메모, } \\
\text { 팩스 작성능력 }\end{array}$ & $\begin{array}{l}\text { 효과적인 직무수행과 의사소통을 위해 적합한 매체를 선 } \\
\text { 택, 활용하여 공식화된 형식으로 메시지를 주고받는 능력 }\end{array}$ \\
\hline & 14.인터뷰 능력 & $\begin{array}{l}\text { 고용주와 면대면 질의응답을 통해 자신의 잠재능력, 책임 } \\
\text { 감, 창의적 사고력, 업무 추진력, 대인관계, 성격 등을 짧 } \\
\text { 은 시간 내에 효과적으로 호소하는 능력 }\end{array}$ \\
\hline
\end{tabular}




\begin{tabular}{|c|c|c|}
\hline \multirow{3}{*}{$\begin{array}{l}\text { 직무관련 } \\
\text { 커뮤니케이션 }\end{array}$} & 15.업무 보고서 작성능력 & $\begin{array}{l}\text { 해당 업무의 진행상황과 문제점, 최종목표까지 도달하기 } \\
\text { 위해 수행해야할 과제 등을 상급자 및 팀원들에게 주기적 } \\
\text { 으로 보고하는 능력 }\end{array}$ \\
\hline & 16.설득 및 협상능력 & $\begin{array}{l}\text { 관련 정보와 다른 사람들의 다양한 의견을 비판적으로 논 } \\
\text { 의 및 대화함으로써 상대방을 이해시켜 최선의 해결책이 } \\
\text { 나 합의를 이끌어 내는 능력 }\end{array}$ \\
\hline & 17.제안서 작성능력 & $\begin{array}{l}\text { 고용주에게 과제 (일)을 언기 위해 자신이(제안자가) 프로 } \\
\text { 젝트를 수행할 최적의 사람 또는 조직이라는 것을 확신시 } \\
\text { 키는 능력 }\end{array}$ \\
\hline \multirow{2}{*}{$\begin{array}{c}\text { 발표 } \\
\text { 커뮤니케이션 }\end{array}$} & 19.프레젠테이션능력 & $\begin{array}{l}\text { 다른 사람에게 다양한 매체를 통해 자신의 연구결과나 아 } \\
\text { 이디어를 명확하게 전달하는 능력 }\end{array}$ \\
\hline & 20.효과적 PPT작성능력 & $\begin{array}{l}\text { 연구결과 및 사업계획 등을 PPT 슬라이드를 활용하여 청 } \\
\text { 중들이 쉽고 명확하게 이해할 수 있도록 작성하는 능력 }\end{array}$ \\
\hline
\end{tabular}

선정된 공학커뮤니케이션 교육과정에서 다루어야 할 내용은 전체 5 영역 18 개의 내용으로 하 나의 교과목에서 다루기에는 내용이 많다. 따라서 교육내용 구성요소의 특성을 고려하여 교육과 정을 통합하여 운영가능하다. 예컨대, 일반커뮤니케이션 영역의 논리적 글쓰기, 창의적 글쓰기, 비판적 글쓰기를 목적에 부합하는 글쓰기라는 주제로 통합하여 운영가능하고 취업커뮤니케이 션의 자기소개서 작성, 이력서 작성, 인터뷰는 취업준비커뮤니케이션이라는 주제로 통합 운영가 능하다. 다만, 한 학기동안 이루어지는 교과목에서 모든 내용을 깊이있게 다루기는 어려우므로 교육내용을 통합 조절할 때에는 시간 배분에 초점을 두기보다는 대상학생들의 학년과 관심분야 에 따라 집중해서 다루어야 할 영역을 먼저 결정하여 주차별 계획을 세워야 할 것이다.

교육내용을 결정할 때 고려해야 할 사항으로 학생들에게 제공되는 4 년간의 교육과정에서 공 학커뮤니케이션의 내용 구성요소를 다루는 다른 교과목이 있는지를 검토해야 한다. 예를 들어, 학술연구논문작성법은 졸업논문작성법 또는 종합설계교과목에서 다루기도 한다. 이럴 경우에는 논문작성법보다는 학술데이터베이스 활용법에 초점을 둘 수 있다. 또한 대상으로 하는 학생들의 학년에 따라 선수학습수준이 다를 수 있기 때문에 사전에 학생들의 출발점행동을 파악하여 교 육내용의 수준과 강의내용의 유형을 달리 구성할 필요가 있겠다.

\section{V. 결론}

본 연구에서는 과학기술분야의 인재상의 변화에 따른 공학교육의 변화에 맞추어 공학자가 갖 추어야 할 핵심역량으로써 공학커뮤니케이션 능력을 향상시킬 수 있는 교육과정 구성체계를 개 발하였다. 그동안 공학계열 대학에서는 공학커뮤니케이션 교과목을 개설하여 운영해 오고 있는 대학들이 상당수 있어왔다. 그러나 교과목이 공학과 커뮤니케이션의 융합교과목으로써 해당 교 
과목을 담당할 전문가가 국내에 많지 않다보니, 해당 교과목의 운영 현황이 크게 두 가지 유형으 로 구분되었다. 대학필수교과목으로 운영하고 있는 글쓰기 교과목을 담당해 오고 있는 한국어문 학 교수들이 운영하는 경우, 일반 글쓰기 기초와 토론에 초점을 둔 학습활동이 주가 되었다. 공 학을 전공한 교수들이 운영하는 경우, 실험보고서, 제안서, 발표 등과 같이 공학분야에서 활용도 가 높고 교수자 본인들이 잘 가르칠 수 있는 내용 위주로 교육내용을 구성하는 것이다. 다시 말 해서, 한국어문학 전공자가 가르칠 경우, 일반역량으로써 글쓰기와 말하는 능력에 초점을 둔 교 육내용으로 구성하여 운영하였고, 공학전공자가 가르칠 경우에는 이론보다는 결과위주의 실천 적인 교육내용으로 구성하여 운영하였다. 이러한 현상은 학습자의 요구에 부합한다기 보다 교수 자 중심의 교육내용 구성으로써 학습성과가 누가 운영하는 교과목을 운영했느냐에 따라 달라질 수 있으며 학습자의 요구와 부합하지 않을 경우 학습성취도 또한 상당히 다를 수 있음을 시사하 였다. 이에 본 연구에서는 교육의 수혜자인 학습자들의 요구와 커뮤니케이션 교과목 교수경력이 있는 전문가의 요구에 기반하여 공학커뮤니케이션의 교육과정 구성체계를 개발하였으며 이 연 구결과는 공학계열의 대학에서 운영하고 있는 공학커뮤니케이션 교육목표 및 내용구성에 실천 적인 가이드라인을 제공해 주리라 기대된다.

추후 연구에서는 개발된 교육과정 구성체계에 기반한 구체적인 교육내용 및 사례 개발 연구 가 이루어져야겠다. 또한 해당 교육프로그램을 실제 운영해 보고 그 교육적 효과에 대한 검증이 이루어져야겠다. 그리고 공학커뮤니케이션 교과목의 특성상 이론적 학습과 함께 학습자들의 실 천적 수행능력을 향상시킬 수 있는 교수법에 대한 연구도 추후 이루어져야겠다. 


\section{참고문헌}

권성규(2010). 공학교육방법: 공대생 글쓰기 과목에서 가르칠 내용. 공학교육연구, 13(1), 3-16. 신선경(2009). 공학인증과 공학 글쓰기 교육의 새로운 모델. 반교어문연구, 27, 64-88.

오윤선(2006). 이공계 대학생을 대상으로 한 글쓰기 교수법의 방향. 어문연구, 34(4), 427-447. 오정숙(2010). 커뮤니케이션 교육과정 개발을 위한 대학생의 커뮤니케이션 역량 규명 델파이 연

구. 교육공학연구, 26(2), 241-266.

이효녕 외(2009). 공학 계열 글쓰기 교육에 대한 인식조사. 중등교육연구, 57(1), 167-186.

이희정(2009). 한국대학에서의 이공계계열 글쓰기 교육의 현황과 과제. 한민족문화연구, 31, 561-594.

장욱희, 이상호(2009). 대학생의 역량과 구직성과와의 관계에 관한 연구. 인사관리연구, 33(1), $31-59$.

진성희, 김태현(2010). 공과계열 대학생을 위한 맞춤형 테크노 리더십 캠프 프로그램 개발. 공학 교육연구, 13(6), 111-121.

최상민(2009). 공학인증제'와 글쓰기 교육: 전남대 글쓰기 교재 분석을 중심으로. 한국언어문학, 68, 165-186.

Burroughs, N. F., Marie, V., \& McCroskey, J. C. (2003). Relationships of self-perceived communication competence and communication apprehension with willingness to communicate: A comparison with first and second languages in Micronesia. Communication Research Reports, 20(3): 230-239.

Curran, P. J., West, S. G., \& Finch, J. F. (1996). The robustness of test statistics to nonnormality and specification error in confirmatory factor analysis. Psychological methods, 1(1), 16.

Dobrin, S. I., Keller, C. J., \& Weisser, C. R. (2008). Technical communication in the twenty-first century. Upper Saddle River, NJ Pearson Education.

Johnstone, B., \& Watson, A. (2004). Participation, Reflection and Integration for Business and Lifeling Learning. Journal of Workplace Learning, 16, 53-59.

Kolmos, A., \& Holgarrd, J. E. (2008). Learning styles of science and engineering students. Proceeding of European Society for Engineering Education, Aalborg, DK: SEFI.

Lee, W. E. III \& Lunsford, D. (2007). Communication apprehension in undergraduate engineering students: The influence of the performing arts and related activities. 
Proceedings 2007 ASEE Conference, Honolulu, HW: ASEE.

MaKay, M., Davis, M., \& Fanning, P. (1995). Massages: The Communication Skills Book Oakland, CA: New Harbinger.

Martilla, J. A., \& James, J. C. (1977). Importance-performance analysis. The journal of marketing, 77-79.

P’Rayan, A., \& Shetty, R. T. (2008). Developing engineering students' communication skills by reducing their communication apprehension. English for Specific Purposes World, $4(20), 1-24$.

Pfeiffer, W. S., \& Adkins, K. E. (2010). Technical Communication: A practical approach Upper Saddle. River, NJ: Prentice Hall.

Secretary's Commission on Achieving Necessary Skills (SCANS) (1991). What Work Requires of Schools: A SCANS report for America 2000. US Department of Labor, Washington, DC.

\section{* 논문접수 2015년 2월 2일 / 1차 심사 2015년 3월 6일 / 게재승인 2015년 3월 16일}

* 김태현: 충북대학교 컴퓨터교육과를 졸업하고 서울대학교 교육학과에서 교육공학 전공으로 박사학위를 취득하였다. 현재 국가평생교육진흥원에서 근무하고 있으며 주요관심분야는 이러닝 교수설계, 모바일 러닝, 학습분석 등으로 관련 분야에 대한 연구를 수행 중에 있다.

*E-mail: taehyunkiml3@gmail.com

* 진성희: 경인교육대학교를 졸업하고 서울교육대학교에서 석사학위를 취득하였으며, 서울대학교 교육학과에서 교육공학 전공으로 박사학위를 취득하였다. 현재 인하대학교 미래융합교육원 조교수로 있으며 주요관심분야는 공학교육, 디자인 씽킹(창의성 증진) 교수법, 디지털텍스트의 시각적 설계, 최소한의 노력으로 교육적 효과를 산출할 수 있는 적정 교수법 (appropriate teaching strategies) 등으로 관련 분야에 대한 연구를 수행 중에 있다.

* E-mail:shjin@inha.ac.kr 


\title{
Abstract
}

\section{Development of Needs-driven Learning Contents for Engineering Communication Course}

\author{
Kim, Tae-Hyun* \\ Jin, Sung-Hee
}

With globalization of technology and convergence among academic fields, the trend of engineering education has been changed from emphasizing individual expertise into focusing on developing professional skills. In order to satisfy these social needs, a course of engineering communication has been operated for enhancement of engineers' communication competency. However for a reason that there were not so many specialists in this field, the course has been operated depending on professor's background knowledge and experience. Therefore, the purpose of this study was to develop the customized learning contents for engineering communication courses that fitted in needs for students and experts. For the research, domestic and international educational programs related to engineering communication were analyzed by means of searching for the theoretical background for engineering communication. As a result, the educational framework was drawn. In order to confirm the validity of the educational framework, needs analysis was conducted to 11 professors who were in charge of engineering communication more than 5 semesters and 95 undergraduate students majoring in engineering. Through analysis of importance and performance matrix about content constructs of engineering communication, 5 kinds of areas and 18 kinds of contents constructs were selected. The constructs were 4 academic writings, 5 basic communications, 4 communications for employment, 3 job-related communications and 2 communications for presentation. The results were expected to suggest practical guidelines for constructing learning contents of engineering communication courses,

Key words: engineering communication, technical communication, learning contents, needs analysis, importance-performance analysis

** Corresponding author, Inha University, Academy of Convergence Education, Assistant Professor 